\title{
SIMPLIFIED CHARACTERIZATION TECHNIQUES FOR (SUB) TROPICAL BASE MATERIALS AND MODELLING
}

\author{
A. A. ARAYA \\ Ethiopian Roads Authority, Addis Ababa, Ethiopia.
}

\begin{abstract}
Most pavements in developing countries are designed based on index material properties related to a single design chart, restricting the incorporation of marginal and new materials for which the index property data sets are not available. To promote the introduction of naturally abundantly occurring marginal materials as well as recycled road base subbase materials in the road construction in those countries, mechanical behaviour of granular material can be used for design. The mechanical properties of these materials can be obtained from a simplified repeated load California bearing ratio (RL-CBR) characterization technique. An extensive RL-CBR characterization has been carried out on (sub) tropical base and subbase granular materials. A finite element method analysis has been attempted for the purpose of modelling the RL-CBR and derives an equivalent resilient modulus of the sample material. Furthermore, a cyclic triaxial test was carried out to validate the result of the RL-CBR. Through the RL-CBR characterization technique not only the practical accessibility of characterizing the mechanical behaviour of unbound granular materials is enhanced but also the effect of moisture content and degree of compaction on these behaviours is well demonstrated.
\end{abstract}

Keywords: Granular road base, mechanical behaviour, modelling, repeated load CBR, triaxial test.

\section{INTRODUCTION}

A road pavement in general is a layered structure of selected materials placed on top of a natural or filled subgrade. The pavement layers comprise of the top asphalt layer in case of paved roads, base and subbase with/without an underlying capping layer, as shown in Fig. 1. The granular base and subbase layers have to perform as both a short-term construction platform and also as a long-term durable structure for the overlying pavement [1]. In most pavements, in developing countries, the main structural element is formed by granular layers with thick base and subbase layers placed over the subgrade (Fig. 1(b)). For economic reasons the asphalt cover, if any, is very thin with a limited structural function. It mainly provides protection against water ingress and often the asphalt cover is omitted altogether.

In many of the mechanistic pavement design procedures used today, granular materials do not feature strongly. These design procedures focus on designing the asphalt layer, given the subgrade condition, the traffic loadings and the climatic conditions. This is due to the fact that in the industrialized countries, where these design procedures originate, the main structural element is the asphalt layer and the significance of the granular base and subbase is virtually reduced to that of a working platform. As Sweere [2] noted, the Shell Pavement Design Manual is a clear illustration of this: through the fixed ratio of the stiffness of the (sub)base and the subgrade the structural contribution of the unbound granular (sub)base is limited and granular materials hardly play a role in the design.

Pavements in developing countries do have only thin asphalt surfacing, and as a consequence, the granular base and subbase layers provide the bulk of the bearing capacity. Despite the extensive use of granular materials, in the empirical pavement design procedures employed in those countries, granular base and subbase materials are often not used to their fullest extent. Moreover, though those light-structured pavements are designed for relatively low-traffic intensities, they are usually subjected to very heavy traffic due to excessive 


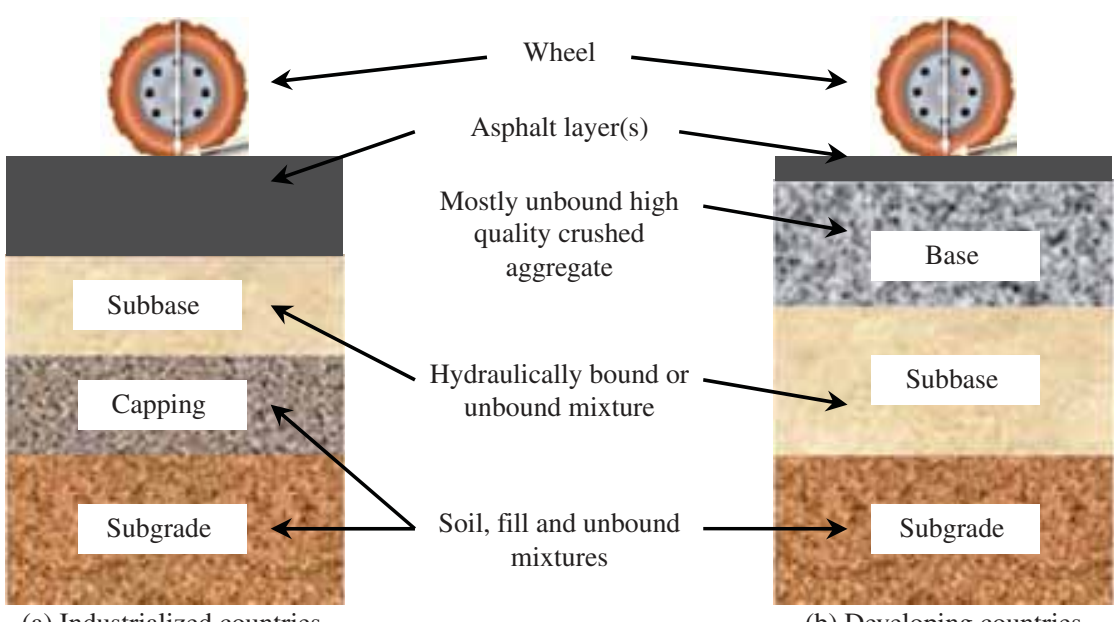

(a) Industrialized countries

(b) Developing countries

Figure 1: Schematic pavement structure typical sections and material options.

overloading and severe climatic conditions such as high temperatures, high-moisture contents, and wet and dry seasons.

In such pavements, the granular layers have the following roles:

- ability to carry a significant portion of the load applied by a vehicle (during construction and service time) and spread to a magnitude that will not damage the underlying layers, particularly the subgrade;

- resistance to the build up of permanent deformation within each layer;

- provision of an adequately stiff layer on which the overlaying layers can be compacted;

- provision of an adequately durable and stiff layer to support any overlaying layers in the long term during in-service conditions.

To fulfil these requirements and establish more rational pavement design and construction criteria, it is essential that the response of granular layers under traffic loading is taken into consideration and thoroughly understood. It becomes very important to properly characterize the behaviour of unbound aggregate layers and subgrade soils of the layered pavement structure in order to predict pavement responses, which is essential in the framework of a mechanistic-empirical (M-E) pavement design approach. The M-E design process relies on inputs such as the resilient (stress-dependent elastic) modulus and Poisson's ratio of the material.

In contrast, day-to-day engineering practice specifies and constructs roads based on a completely different set of parameters with very little correlation between the M-E design inputs and the common engineering parameters of the material. The factors impeding the more fundamental and mechanical approach of the behaviour and performance of granular bases and subbases are basically related to the complexity of the characterization techniques, for example, cyclic loading triaxial tests, required to determine the stress-dependent mechanical behaviour of granular materials.

The content of this paper is part of a research conducted to develop a characterization technique for the mechanical behaviour of unbound granular base and subbase pavement 
materials (mainly (sub) tropical materials) that is more easily accessible to practice. This is to promote the introduction of M-E design methods in developing countries. In addition, it also provides a thorough understanding of the fundamental behaviour of unbound base and subbase materials under traffic loading.

\section{MECHANICAL BEHAVIOUR AND MATERIAL MODELLING}

In flexible pavements, especially when the surface is a thin asphalt layer or surface seal, the role of granular layers is very important in the general performance of the structure since the load is distributed to the subgrade mainly through these layers. Over the past four decades, many researchers have been investigating the resilient behaviour of granular materials as the shift from the empirical to the mechanistic design of pavement gained popularity. Many factors were determined to have an effect on the resilient modulus of granular materials. The state of stress was found to have the most influence on the resilient behaviour. Hicks [3]; Smith and Nair [4]; Sweere [2]; and Huurman [5] have shown that the resilient modulus increases with an increase in confining pressure. In contrast, Brown [6] reported a significant effect of the deviator stress, especially at high stress levels. Many other factors such as density, moisture content, stress history, number of load cycles, particle shape and mineralogy, and load characteristics (frequency and load sequence) have been found to impact the resilient behaviour of granular materials. A detailed discussion of these parameters can be found in LeKarp et al. [7].

Most of these investigations have been carried out using facilities such as the Repeated Load Triaxial (RLT) test and Hollow Cylinder Apparatus (HCA). However, such specialist tests are considered too complex and unaffordable to implement in routine road construction projects particularly in developing countries. Even in the industrialized countries such tests are implemented mainly for research purpose but hardly used in day-to-day engineering practice. The existence of the gap between research and industry-based practice reveals the absence of appropriate characterization techniques. These characterization techniques developed for research purposes have economical and practical limitations that prevent their widespread use. Edward [1] reports that these barriers include level of complexity, skills or trainings required prior to use, availability and affordability. In contrast, despite their worldwide acceptance and existence for long time index testing, such as California bearing ratio (CBR), being too empirical, have technical limitations to be used in the M-E design methods.

\section{THE PRINCIPLE OF REPEATED LOAD CBR TEST}

The standard CBR test is a long established extensively applied test that yields an empirical strength property of granular road materials. The repeated load CBR (RL-CBR) test is developed to take the advantage of the widespread familiarity of the standard CBR test and excel the already developed extensive experience.

The principle of the RL-CBR test is similar to the standard CBR test but RLs are applied. Upon multiple repetitions of the same magnitude of loading granular materials come to a state in which almost all strain under a load application is recoverable. The permanent (plastic) strain ceases out to exist or becomes negligible and the material behaves basically elastic, that is, with stable recoverable deformation. This is represented in Fig. 2. From the applied stress and the measured recoverable strain an elastic modulus can be estimated. Details of the test setup and test procedure can be summarised as follows.

By recording the load and displacement, and plot in $x-y$ axes, a graph similar to Fig. 2 is obtained from which load levels and total, elastic (recoverable) and plastic (permanent) 


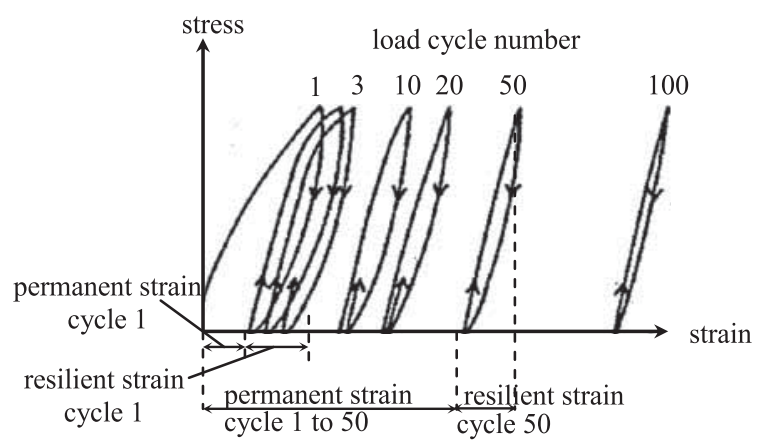

Figure 2: Stress-strain behaviour of a granular material under repeated loading.

deformations under the penetration plunger can be obtained. The elastic modulus $(E)$ is computed from the applied plunger stress $\left(\sigma_{p}\right)$ and the elastic deformation of the specimen $(u)$ in the final load application. The stress $\sigma_{p}$ can be calculated from the applied plunger force $(F)$ and the contact area of the plunger $(A)$.

The standard CBR test is initially developed to determine strength properties of fine subgrade soils. Through time it is accepted as a standard test for base and subbase materials finer than $22.4 \mathrm{~mm}$. In this research, as presented in chapter 3 in detail, by scaling up the mould and the plunger sizes the test is adopted to characterize materials as coarse as $0 / 45 \mathrm{~mm}$. Moreover, it is attempted to determine the stiffness modulus of coarse granular materials by repeating the load application. The purpose of this approach as discussed in [8] is to estimate the stiffness modulus of granular materials, which normally have to be determined from a cyclic load triaxial test, from a simplified test.

It is known that the stiffness modulus of unbound granular base and subbase materials is stress dependent. Therefore, one of the drawbacks to use the CBR test for determination of the fundamental material properties such as the stiffness modulus is its non-uniform complex stress distribution compared with the triaxial test. In general, in a triaxial test system, for specimens with their diameter to maximum grain size ratio being at least 5 , it is assumed that the material is homogenous and the stress distribution is uniform throughout the material excluding the contact effects at the top and bottom end of the sample. This holds true, however, depending on the scale and level of detail one is interested in.

Figure 3 is considered to evaluate the effect of grain size and loading condition on the stress distribution in unbound granular specimens and to compare between triaxial and CBR specimens. In this figure, three cases are presented, that is, coarse aggregate triaxial specimen, coarse aggregate in CBR mould and sand in CBR mould. In these three cases, let us consider that the coarse aggregates are materials that are used in this research; thus, $0 / 45 \mathrm{~mm}$ base and subbase aggregates. The specimen sizes are also the sizes adopted throughout the research, that is, 300-mm diameter with $600-\mathrm{mm}$ height triaxial specimens and 250-mm diameter by $200-\mathrm{mm}$ height CBR specimens.

This implies that, say at a macro-scale, see Fig. 4(a), the unwritten rule that says the minimum specimen dimension should be at least five times the maximum grain size in order to consider the specimen as a bulk and homogenous material, is satisfied for the coarse aggregate triaxial specimen. The enclosed volume of the coarse aggregate and sand in the CBR mould may just be considered as a bulk. However, when the dimension of the loading plunger is taken into account this is surely no longer the case for the coarse aggregate in the CBR test 


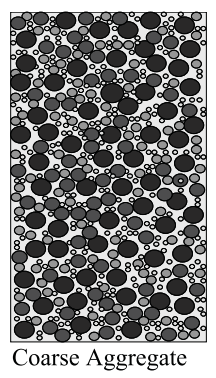

(a)

$$
\begin{aligned}
& \text { Round } 40 \mathrm{~mm} \\
& \text { Round } 30 \mathrm{~mm} \\
& \text { Round } 20 \mathrm{~mm} \\
& \text { Round } 10 \mathrm{~mm}
\end{aligned}
$$

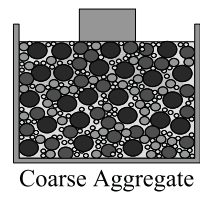

(b)

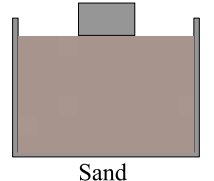

(c)

Figure 3: Coarse aggregate triaxial specimen and coarse aggregate and sand-filled CBR samples.

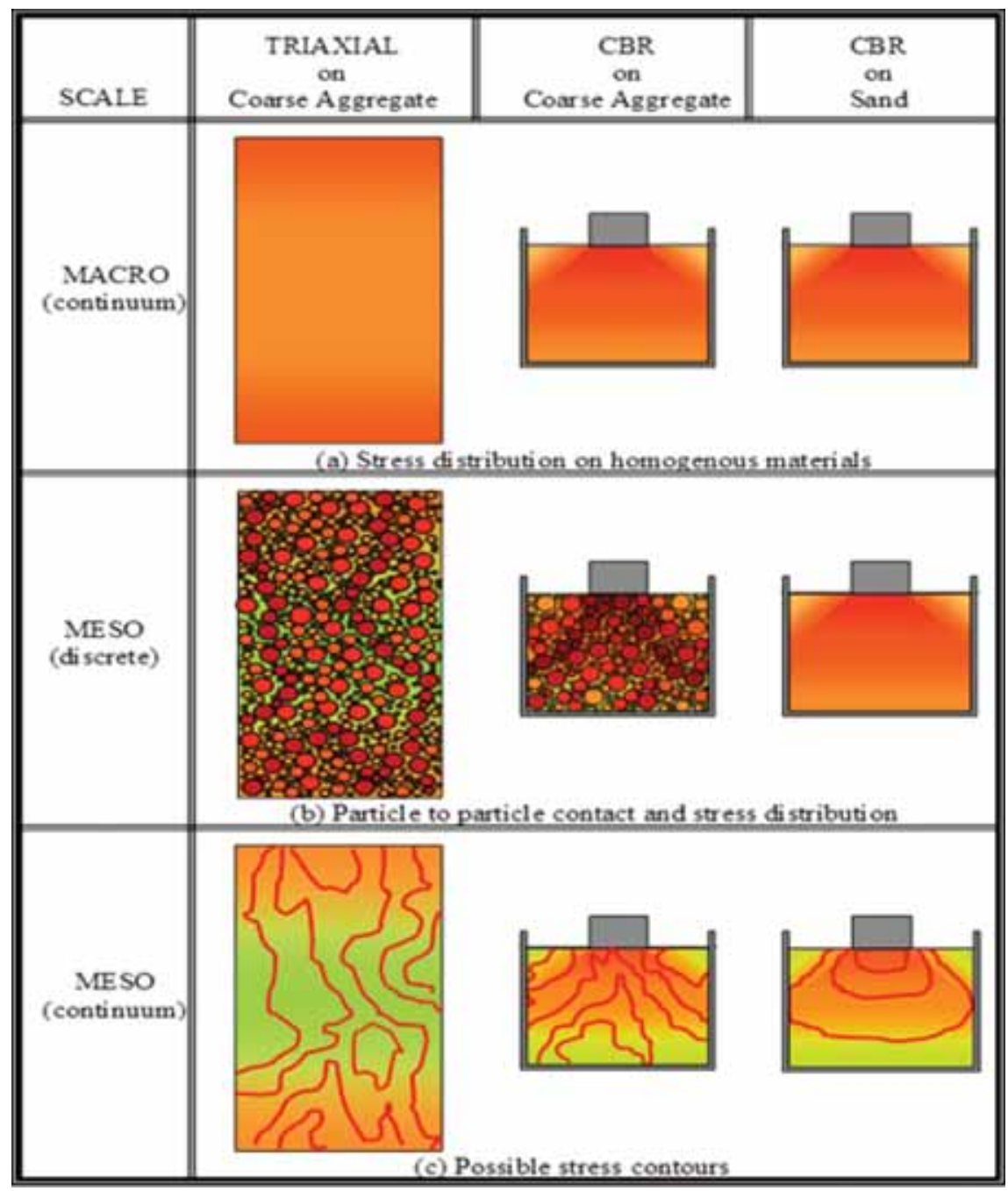

Figure 4: Scale of investigation, particle to particle contact and stress distribution in triaxial and CBR specimens. 
despite the use of an enlarged plunger. Moreover, the penetration plunger load in the CBR results in a non-uniform stress distribution in the specimen as shown in Fig. 4(a). Therefore, it can be concluded that at macro-scale the assumed homogenous material results in a uniform stress distribution for the triaxial specimens, at least at the mid-height of the specimen, and hence a uniform stress-dependent stiffness modulus known as 'resilient modulus'. For the CBR specimen, however, it gives a non-uniform stress distribution, and hence the specimen will exhibit a non-uniform material stiffness modulus.

If we observe the stress condition at a more detailed scale, say meso-scale, the random grain pattern and the grain to grain contact will play a significant role in the stress distribution, see Fig. 4(b). The grain to grain contact results in a significant stress distribution variation for the coarse aggregate materials for both the triaxial as well as the CBR specimen as shown in Fig. 4(c). In the sand-filled CBR mould, the grain to grain contact does not influence the stress much, and hence the stress-dependent stiffness modulus. It should be clear that the intention is not to make an argument that both triaxial and CBR specimens are equally inaccurate or approximations. It is to give a good picture that considering a given granular specimen as a bulk is rather dependent on the scale one is looking at and the detail and level of accuracy one is interested in.

It should also be clear that the purpose of RL-CBR testing is not to determine a pinpoint accurate stiffness modulus of granular materials but to get an approximate estimate of acceptable accuracy from a simpler characterization technique. The research starts from the concept that the cyclic triaxial test is too complex for the purpose of, say, pavement design in developing countries. Thus, instead of zooming-in from macro-scale $\rightarrow$ meso $\rightarrow$ micro $\rightarrow$ nano-scale in Materiomics ${ }^{1}$, the approach goes in opposite direction zooming-out to a more general say 'global' scale. Where the macro-scale is the scale that most conventional soil mechanics and pavement engineering applications are dealt with.

At the 'global' scale, the variation of the stiffness modulus of the material in the CBR test is replaced by an average, representative or equivalent modulus for the bulk sample. In other words, this averages not only the stress variation due to the grain pattern but also due to the variation of stress distribution from the penetration load. To reflect the scale deviation from the common macro-scale, the conventional term 'Resilient Modulus' of the granular material is replaced with an 'Equivalent Modulus' for the material stiffness property investigated by the RL-CBR.

In the research, RL-CBR tests are performed on various course granular materials ranging from good-quality crushed stone to rather marginal subbase ferricretes (FCs) and recycled mix granulates in order to investigate its suitability as a simple to perform test to estimate mainly the equivalent modulus and to a certain extent the resistance to permanent deformation for unbound granular materials. The laboratory investigation is carried out in two test techniques: without and with strain gauges. The characterization technique and investigation of the resilient and permanent deformation behaviour of the extensive RL-CBR testing without strain gauge is reported in [8-11]. This paper concentrates on the RL-CBR test with strain gauges for a South African subbase granular material FC.

The FC is a natural gravel obtained from a borrow pit in South Africa. It is natural coarse aggregate relatively week to crushing where its particles are characterized with porous

1 Materiomics is defined as the study of the material properties of natural and synthetic materials by examining fundamental links between processes, structures and properties at multiple scales, from nano to macro, by using systematic experimental, theoretical or computational methods. Wikipedia. Materiomics. [cited 2010 August 17]; Available from: http://en.wikipedia.org/wiki/Materiomics. 
Table 1: Gradation of the ferricrete.

\begin{tabular}{lcccccccccc}
\hline $\begin{array}{l}\text { Sieve size } \\
{[\mathrm{mm}]}\end{array}$ & 45 & 31.5 & 22.4 & 16 & 8 & 4 & 2 & 0.5 & 0.18 & 0.063 \\
\hline$\%$ passing & 100 & 99.1 & 88.8 & 75.2 & 50 & 33.3 & 27.3 & 23 & 16.9 & 10.7 \\
\hline
\end{tabular}

spherical shape and rough surface texture with grading 0/45, Table 1 shows the wet sieve gradation of the material. The iron-rich (sub) tropical FC is characterized as a mineral conglomerate consisting of surficial sand and gravel cemented into a hard mass by iron oxide derived from the oxidation of percolating solutions of iron salts. The RL-CBR test is carried out at varying moisture content (MC) and degree of compaction (DOC). The moulding moisture varies as dry $(5 \%)$, moderate $(7.5 \%)$, wet $(9.5 \%)$ and the DOC varies from $95 \%$ to $100 \%$ of the maximum modified Proctor dry density (MPDD).

\section{REPEATED LOAD CBR TESTING AND MODELLING}

\subsection{RL-CBR testing}

In testing unbound granular materials, the ratio of mould (specimen) size to maximum particle size of the material to be tested is an important factor. To use the coarse granular material at its full gradation the RL-CBR tests are carried out with a large size CBR mould and accordingly a bigger plunger. The large RL-CBR mould used is $250 \mathrm{~mm}$ in diameter, $200 \mathrm{~mm}$ in height with an extension collar of $75 \mathrm{~mm}$ and the penetration plunger of $81.5 \mathrm{~mm}$ in diameter. The RL-CBR test specimens are compacted using the same vibratory compactor apparatus and the same compaction principle as to the $300 \times 600 \mathrm{~mm}$ triaxial specimens [8]; which the results are used to validate the RL-CBR test principle.

To facilitate the extensive experimental research a loading frame with an automated hydraulic actuator was used for the RL-CBR testing. The cyclic loading data and the vertical penetration of the plunger are measured through internal actuator displacement measurement and external vertical deformation Linear variable differential transformer (LVDT). For the case of RL-CBR tests with strain gauges the radial strain of the mould is measured by strain gauges; its schematic representation and the test setup is shown in Fig. 5(a) and (b).

The test is performed in the displacement-controlled mode at a constant displacement rate of $1.27 \mathrm{~mm} / \mathrm{min}(0.05 \mathrm{inch} / \mathrm{min})=0.021 \mathrm{~mm} / \mathrm{s}$ similar to the standard CBR test loading specification [12]. The specimen is loaded, at the standard CBR displacement rate $(1.27 \mathrm{~mm} / \mathrm{min})$, to a predetermined deformation (e.g. $2.54 \mathrm{~mm}$ ) or load level. The load is recorded and unloaded with the same rate $(1.27 \mathrm{~mm} / \mathrm{min})$ to a minimum contact load of 0.5 to $1 \mathrm{kN}(0.1$ to $0.2 \mathrm{MPa})$. The specimen is re-loaded to the same load at the same displacement rate of $1.27 \mathrm{~mm} / \mathrm{min}$, and released once more to the minimum contact load. The maximum and minimum load levels for each cycle are, therefore, kept constant. These cycles are generally repeated for 50-100 load cycles at which the permanent deformation due to the last five loading cycles will be less than $2 \%$ of the total permanent deformation at that point. The load and deformation can be recorded at a required reasonable accuracy rate. The resilient (recoverable) and permanent (unrecoverable) deformation is then measured as shown in Fig. 6. 

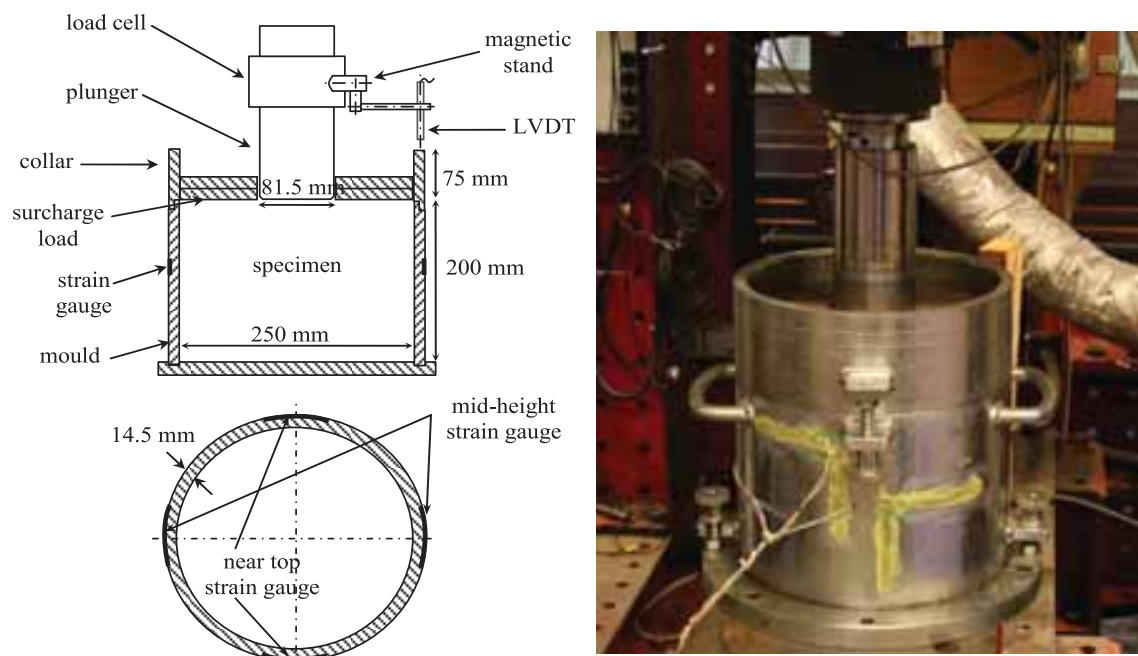

Figure 5: RL-CBR with strain gauges schematic diagram and test setup.

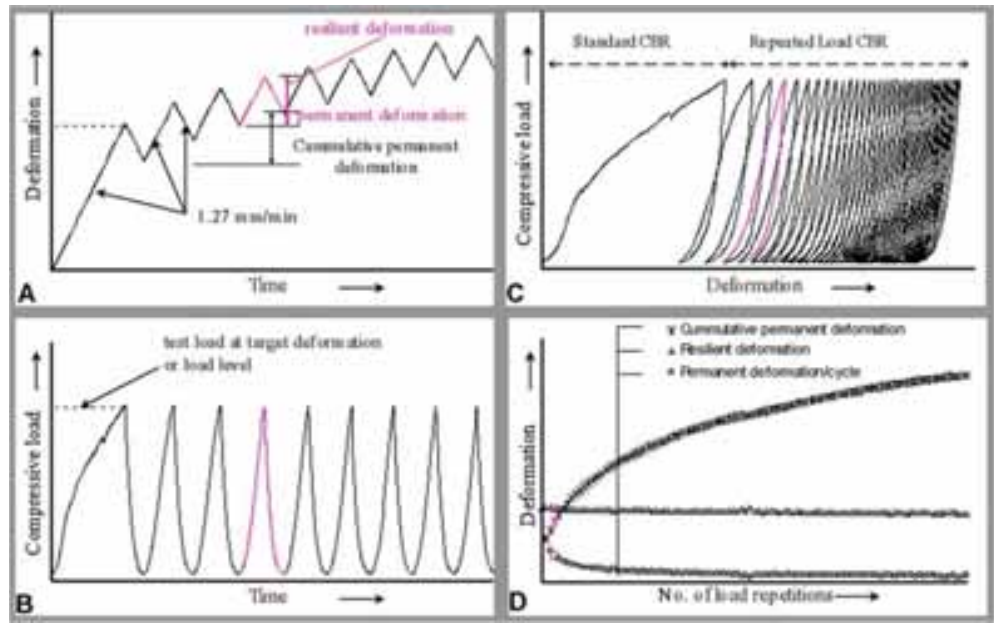

Figure 6: RL-CBR test and typical load-deformation measurements.

In the case of RL-CBR test with strain gauges the specimen confining pressure and hence the state of stress distribution is approximated from deformation of the mould measured through the strain gauges. It is well known that the stiffness modulus of unbound granular materials is stress dependent and the effect of the confining stress is significant. In contrast, the confining pressure is not readily measurable due to the complex nature of the stress state in the CBR mould. However, the compacted specimen will apply a load on the steel mould when loaded. This will result in a deformation of the mould that can be measured by means of strain gauges. The mould lateral strains were recorded for each loading and unloading cycle during the test. The degree of confinement and its effect on the elastic properties of the specimen can then be investigated. 


\subsection{Modelling the repeated load CBR test}

The main purpose of the finite element modelling in this research is to simulate the RL-CBR test through finite element analysis. That is to develop a simplified relation between the unbound granular material elastic properties, mainly the stiffness modulus, with the stresses and deformations obtained. For this purpose a simple linear elastic material property is used in modelling both the granular material and the steel mould confining the granular specimen. For modelling the RL-CBR setup the ABAQUS axisymmetric Finite Element Method (FEM) code is utilized. A linear elastic material property is assumed for the steel mould and the granular material with $210 \mathrm{GPa}$ elastic modulus, $E$, and 0.2 Poisson's ratio, $v$, for the steel mould and varying $E$ and $v$ for the granular material. The plunger is assumed as a rigid body and a contact surface property was defined between the plunger and the granular as hard contact; and the mould and the granular with exponential pressure-overclosure relationship defined in ABAQUS.

For a given property of the granular material a strain controlled is used to simulate the test, that is, a vertical displacement is applied on the rigid plunger. Stresses, strains and deformations throughout the granular material and steel mould, and total load on the plunger has been recorded for each granular material property combination and applied vertical plunger displacement. This data set can be recorded for each node or element of the mesh shown in Fig. 7.

By using non-linear multidimensional least square regression fitting on the finite element analysis data, transfer functions have been developed that relate material properties and the bulk stresses components of the specimen with the laboratory measurable test parameters, that is, the plunger load, plunger deformation and the lateral or tangential mould exterior

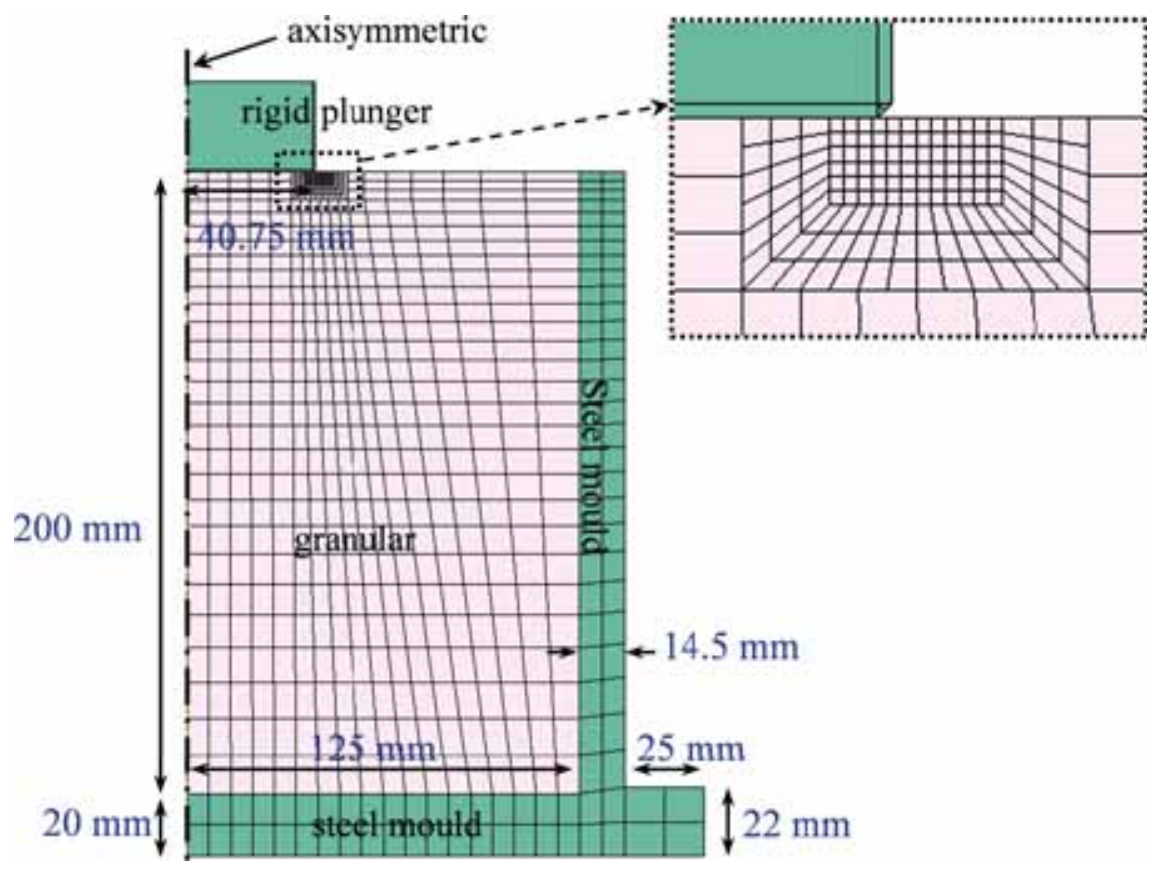

Figure 7: Finite element mesh used in modelling the axisymmetric RL-CBR. 

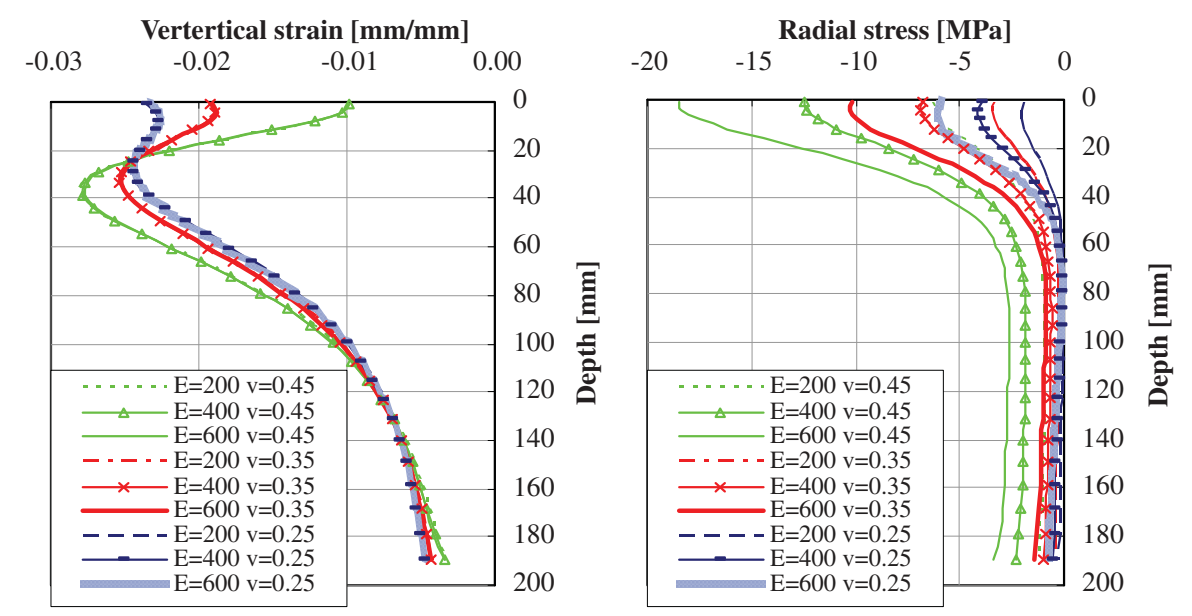

Figure 8: Illustrative stress and strain distribution along the axisymmetric for a $2.5-\mathrm{mm}$ plunger deformation.

strain at mid-height. The vertical and radial stresses of the bulk sample are approximated by weighted average of vertical and radial stresses along the central axis (the axisymmetric) using the vertical deformation in each element along the depth of the sample as weighing factor, eqn (1). This is based on the assumption that the granular material under the plunger is carrying the load most; thus the stress and strains along the central axis are considered as representative of the bulk. An illustrative stress and strain distribution along the depth of the specimen at the axis of symmetry is shown in Fig. 8.

\subsection{Analysis of the finite element model simulation}

The approach of the model analysis (Fig. 9) is set to develop transfer functions that can predict material properties from laboratory measured parameters. The parameters that can be measured from a RL-CBR test with strain gauges are: the plunger load, plunger displacement and the lateral strain at the mould exterior.

The vertical, $\sigma_{v}$, and radial (horizontal), $\sigma_{h}$, stresses of the bulk granular specimen are approximated by the weighted average of the vertical, $\sigma_{v, i}$, and horizontal, $\sigma_{h, i}$, stresses of each element, $i$, along the central axis (the axis of symmetry). These stresses are weighted by the vertical displacements of each element along the depth of the sample (eqn (1)). As the vertical plunger displacement is the governing parameter for all the stresses and strains in the specimen, the vertical displacement, $u_{v, i}$, of each element is used as weighting factor for both the vertical and horizontal stresses.

$$
\sigma_{v}=\frac{\sum \sigma_{v, i} u_{v, i}}{\sum u_{v, i}} \quad \sigma_{h}=\frac{\sum \sigma_{h, i} u_{v, i}}{\sum u_{v, i}}
$$

For a general axisymmetric case, with the $z$-axis representing the central axisymmetric axis, $r$-axis the radial axis and the $\theta$-axis any rotational angle $\theta$ in polar coordinates, the general three-dimensional stress state can be reduced to four independent components. Figure 10 illustrates and defines these strains and the associated stresses in bodies of revolution 

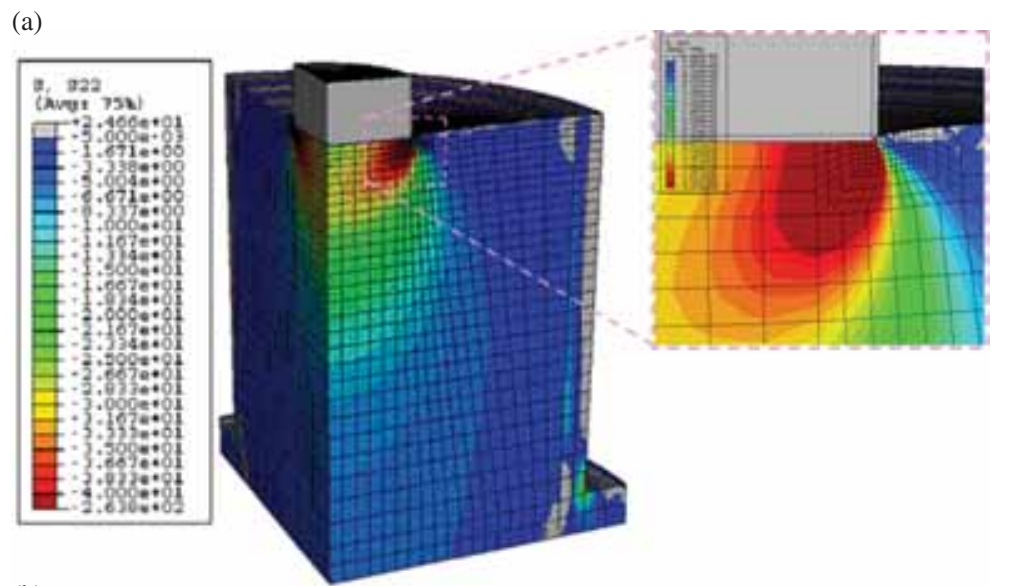

(b)

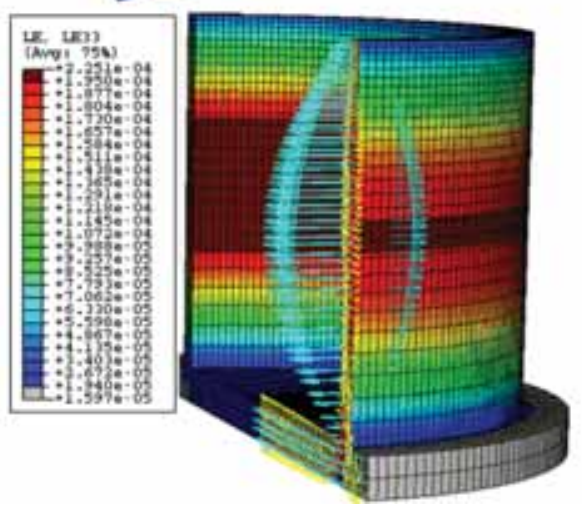

Figure 9: Example of (a) vertical stress distribution on the specimen and (b) lateral strain on the steel mould.

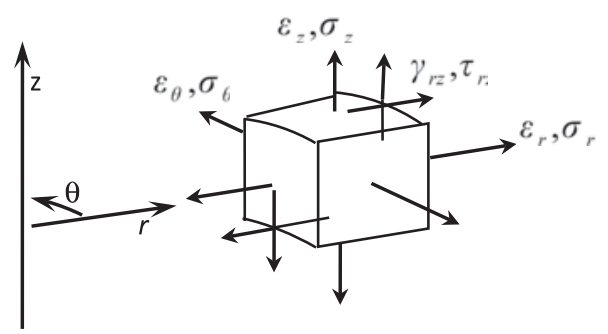

Figure 10: Stress and strain involved in axisymmetric solids.

(axisymmetric solids) under axisymmetric loading. Therefore, the stress-strain analysis in the axisymmetric CBR can be expressed in polar coordinates as eqn (2):

$$
\left[\begin{array}{c}
\varepsilon_{z} \\
\varepsilon_{r} \\
\varepsilon_{\theta} \\
\gamma_{r z}
\end{array}\right]=\frac{1}{E}\left[\begin{array}{cccc}
1 & -v & -v & 0 \\
-v & 1 & -v & 0 \\
-v & -v & 1 & 0 \\
0 & 0 & 0 & 2(1+v)
\end{array}\right]\left[\begin{array}{c}
\sigma_{z} \\
\sigma_{r} \\
\sigma_{\theta} \\
\tau_{r z}
\end{array}\right]
$$


If we consider the special case in the points along the central axis (axisymmetric line) of the CBR model, the stresses and strains are the principal stresses and strains. The stress and strains along axis- $r$ and axis- $\theta$ are identical; thus, eqn (2) can further be reduced into vertical and horizontal components as shown in eqn (3). From eqn (3) the elastic modulus $E$ can be expressed as a function of the vertical strain as shown in eqn (4).

$$
\begin{gathered}
{\left[\begin{array}{l}
\varepsilon_{\mathrm{v}} \\
\varepsilon_{h}
\end{array}\right]=\frac{1}{E}\left[\begin{array}{cc}
1 & -2 v \\
-v & 1-v
\end{array}\right]\left[\begin{array}{l}
\sigma_{v} \\
\sigma_{h}
\end{array}\right]} \\
E=\frac{\sigma_{v}-2 v \sigma_{h}}{\varepsilon_{v}}
\end{gathered}
$$

The equivalent (average) vertical strain $\varepsilon_{v}$ along the central axis is related to the vertical plunger displacement, $u$, per a certain linear dimension, thus $\varepsilon_{v} \approx u / k$. The vertical and horizontal stresses in eqn (4) are the weighted average stresses, eqn (1), in which the vertical stress is mainly related to the average plunger stress, $\sigma_{p}$, thus $\sigma_{v} \approx k^{*} \sigma_{p}$. The Poisson's ratio, $v$, and the horizontal stress are related mainly to the mould strain and the plunger stress and fitted by regression. Finally the four transfer functions, eqns (5)-(8), are developed by means of least square regression fitting on the finite element analyses data with a total of five model parameters $k_{1}$ to $k_{5}$.

$$
\begin{gathered}
\sigma_{v}=k_{1} \sigma_{p} \quad v=k_{2}\left(\frac{\varepsilon_{\operatorname{lm}}}{\sigma_{v}}\right) \\
\sigma_{h}=k_{3} \varepsilon_{\operatorname{lm}} \exp \left(k_{4} / v\right) \quad E_{\text {equ }}=\frac{k_{5}\left(\sigma_{v}-2 v \sigma_{h}\right)}{u_{v}}
\end{gathered}
$$

\begin{tabular}{|c|c|c|c|c|}
\hline \multirow[t]{6}{*}{ Where: } & $\sigma_{v}$ & $=$ vertical stress $[\mathrm{kPa}]$ & $k_{1}-k_{5}$ & $=$ model parameters \\
\hline & $v$ & $=$ Poisson's ratio $[-]$ & $k_{2}$ & $=-120.93[\mathrm{kPa}]$ \\
\hline & $\sigma_{p}$ & $=$ vertical plunger stress $[\mathrm{kPa}]=$ & $k_{4}$ & $=-0.072[-]$ \\
\hline & & $\begin{aligned} & \text { plunger load/plunger area } \\
= & \text { lar strain }\end{aligned}$ & $\sigma_{h}$ & $\begin{array}{l}=\text { horizontal stress }[\mathrm{kPa}] \\
=\text { equivalent modulus }[\mathrm{MPa}]\end{array}$ \\
\hline & $\varepsilon_{l m}$ & $\begin{aligned}= & \text { lateral strain at the mid-height } \\
& \text { of the mould exterior } \\
& \text { [micro-strain] }\end{aligned}$ & $\begin{array}{l}E_{\text {equ }} \\
k_{1} \\
k_{3}\end{array}$ & $\begin{array}{l}=\text { equivalent modulus }[\mathrm{MPa}] \\
=0.368[-] \\
=43.9[\mathrm{kPa}]\end{array}$ \\
\hline & $u_{v}$ & $\begin{aligned}= & \text { vertical plunger } \\
& \text { displacement }[\mathrm{mm}]\end{aligned}$ & $k_{5}$ & $=0.144[\mathrm{~mm}]$ \\
\hline
\end{tabular}

The regressions for the above four relations (eqns (5)-(8)) show a good fit: $r^{2}>0.99$. This fit is of course an indication of relations of the parameters presented in the finite element model through the stiffness matrix (force and displacement relation) and the kinematic compatibility (strain and displacement relation) under the given boundary conditions.

The equivalent stiffness modulus, $E_{\text {equ }}$, of the sample as a bulk is estimated, the same as the elastic modulus of the finite element analysis, as a function of the vertical (axial) stress, horizontal (radial) stress, the Poisson's ratio and exterior strain at mould mid-height as shown in eqns (5)-(8). The advantage of such a model is that it is based from basic theory of elasticity Hooke's law where the model parameters are related to boundary conditions. Moreover, it is expressed as stress-dependent modulus similar to resilient modulus of cyclic load triaxial test models such as the $M_{r}-\theta$ models; thus, can be compared and validated with such model of 
triaxial results. For such purpose a cyclic load triaxial testing has been carried out for the same material.

\section{VERIFICATION WITH TRIAXIAL TEST RESULT}

Cyclic load triaxial testing were carried out on a large scale triaxial setup with a diameter of $300 \mathrm{~mm}$ and a height of $600 \mathrm{~mm}$ specimen for testing the full 0/45 mm coarse material. Similar to the RL-CBR test, the triaxial test was conducted for the FC subbase material with varying the MC and DOC conditions. However, for comparison with the RL-CBR test with strain gauges the cyclic load triaxial test result of the FC material compacted with moderate (7\%) MC at $98 \%$ DOC is presented.

The stress dependency of the resilient modulus was analysed using the simple and wellknown isotropic non-linear $M_{r}-\theta$ model for comparison with the result of the RL-CBR tests with strain gauge. For the FC compacted at moderate MC and $98 \%$ DOC the $M_{r}-\theta$ in log-log scale is presented in Fig. 11.

$$
M_{r}=k_{1} \theta^{k_{2}}
$$

$$
\text { Where } \begin{aligned}
M_{r} & =\text { resilient modulus [MPa] } \\
\theta & =\text { bulk stresses }=\sigma_{1}+\sigma_{2}+\sigma_{3}[\mathrm{kPa}] \\
k_{1} \& k_{2} & =\text { model parameters }
\end{aligned}
$$

To obtain stress-dependent behaviour from the RL-CBR test with strain gauges, large numbers of tests have been carried out at various plunger load levels. For the FC with similar compact conditions eight tests at different load level are conducted. From the RL-CBR laboratory test setup, described earlier three parameters were measured: the average plunger stress, $\sigma_{p}$, the plunger vertical deformation, $u_{v}$, and the exterior strain at mould mid-height, $\varepsilon_{m t}$. The equivalent modulus $\left(E_{\text {equ }}\right)$ is then computed using the transfer functions in eqns (5)-(8), developed from the finite element analysis, with deviator values of $\sigma_{p}, u_{v}$ and $\varepsilon_{m t}$ between the maximum of loading and minimum of unloading of the last five cycles of the 100 cycles. The equivalent modulus is plotted verses the bulk stress, $\theta=\sigma_{v}+2 \sigma_{h}$ where $\sigma_{v}$ and $\sigma_{h}$ are in absolute values of a stress state of a specimen under testing.

In Fig. 12A, the $E_{\text {equ }}-\theta$ model is presented along with the $M_{\mathrm{r}}-\theta$ model of the triaxial test result from Fig. 11. It can be recognized that the equivalent modulus from the RL-CBR test with strain gauge provides the stress-dependent resilient behaviour of the material. The stress state of a RL-CBR test specimen is uncontrolled and generally at a very high stress level due to the high confinement from the steel mould, which results higher equivalent modulus compared

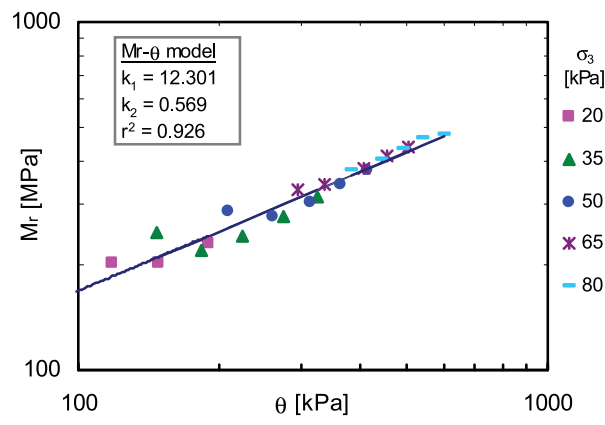

Figure 11: Triaxial resilient modulus as a function of bulk stress, $\theta$ and confining stress, $\sigma_{3}$. 

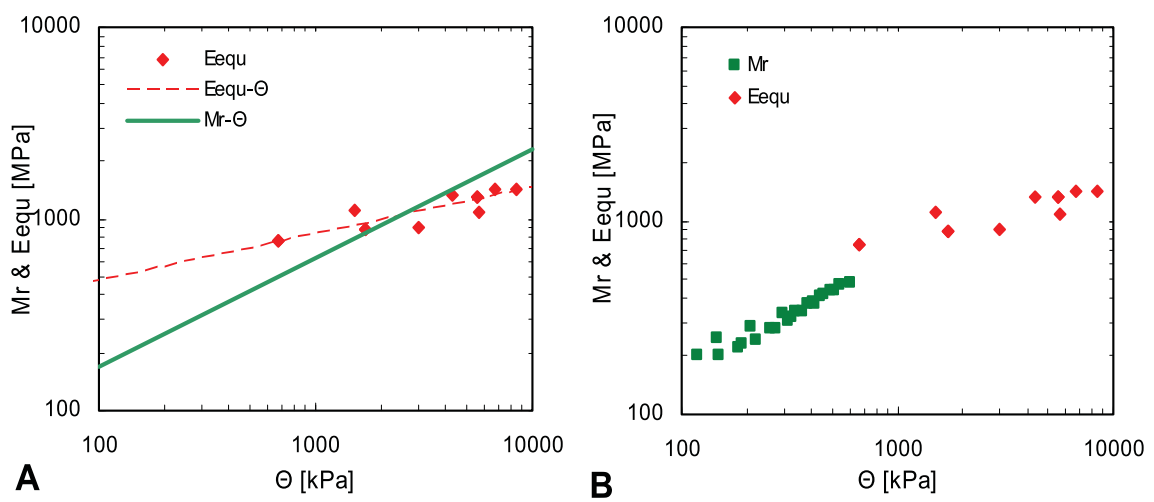

Figure 12: Cyclic triaxial test resilient modulus and RL-CBR test equivalent modulus.

with the resilient modulus of the triaxial. In addition, the $E_{\text {equ }}-\theta$ model shows less stress dependent, or a gentle slope, than the $M_{r}-\theta$. However, when granular materials loaded at much higher stress levels close to failure, the resilient modulus tends to decrease its stress dependency.

Figure 12B shows the equivalent modulus of the RL-CBR test appears as a continuation of the resilient modulus of the triaxial data with more scatter and at high stress level. This indicates that the RL-CBR test is a more complex form of a triaxial test that can provide a good estimate of the stiffness modulus.

\section{CONCLUSION}

In this paper, an intermediate (between the fundamental cyclic triaxial test and the traditional standard CBR test) method of characterization of unbound granular materials, the RL-CBR test, was discussed. It was shown that a good estimate of stress-dependent modulus of the FC granular subbase can be obtained with this characterization technique. The method can thus be used to characterize and estimate the resilient modulus of unbound granular materials, which can be used as an input in mechanistic design procedures, in the absence of fundamental test results.

It should be clear that non-linear finite element models may be developed, as unbound granular materials have non-linearity behaviour. However, the intension of the study is to investigate an alternative simple way of characterization technique that can be implemented in common road engineering laboratories than assessing and modelling advanced material behaviours. Indications are that such advanced models will strongly contribute to the understanding of the stress-strain development in the complex CBR specimen and may provide a more fundamental material behaviour.

The usefulness and characterization techniques of an intermediate testing - the RL-CBR (less fundamental but better than the index tests) are demonstrated for approximation of mechanical behaviour of unbound granular materials employed in developing countries. It was shown that a good estimate of the stress-dependent equivalent modulus of the FC subbase material can be obtained with the RL-CBR testing with strain gauge.

\section{ACKNOWLEDGEMENT}

The research was funded by Delft University of Technology and conducted at the Road and Railway Engineering Laboratory of the Delft University of Technology. The author wishes to acknowledge the full support of the promoter Prof. Dr. Ir. A.A.A. Molenaar and Prof. Kim Jenkins, University of Stellenbosch for supporting the transportation of the FC from South 
Africa. Acknowledgement also goes to the AFCAP (African Community Access Program) for sponsoring the publication of this article, which has a great impact in disseminating knowledge and innovation.

\section{REFERENCES}

[1] Edwards, J.P., Laboratory Characterization of Pavement Foundation Materials, in Centre for Innovative and Collaborative Engineering (CICE), Loughborough: Loughborough University, 2007.

[2] Sweere, G.T.H., Unbound Granular Base for Roads, Faculty of Civil Engineering and Geosciences, Delft University of Technology: Delft, 1990.

[3] Hicks, R.G., Factors Influencing the Resilient Response of Granular Materials, University of California at Berkeley: Berkeley, 1970.

[4] Smith, W.S. \& Nair, K., Development of Procedures for Characterization of Untreated Granular Base Coarse and Asphalt Treated Base Course Materials, Rep. No. FHWARD-74-61, Federal Highway Administration: Washington, DC, 1973.

[5] Huurman, M. Permanent Deformation in Concrete Block Pavements, Delft University of Technology: Delft, 1997.

[6] Brown, S.F., Repeated load testing of a granular material. Journal of the Geotechnical Engineering Division, 100(7), pp. 825-841, 1974.

[7] Lekarp, F., Isacsson, U. \& Dawson, A., State of the art. I: resilient response of unbound aggregates. Journal of Transportation Engineering, ASCE, 126(1), pp. 66-75, 2000. doi: http://dx.doi.org/10.1061/(ASCE)0733-947X(2000)126:1(66)

[8] Araya, A.A., Characterization of Unbound Granular Materials for Pavements, $\mathrm{PhD}$ Dissertation, Delft University of Technology, Delft, 2011.

[9] Araya, A.A., Molenaar, A.A.A. \& Houben, L.J.M., Characterization of unbound granular materials using repeated load CBR and triaxial testing. In GeoShanghai International Conference, ASCE, Shanghai, China, 2010.

[10] Araya, A.A., Molenaar, A.A.A. \& Houben, L.J.M., A realistic method of characterizing granular materials for low-cost road pavements. In the 11th International Conference on Asphalt Pavements (ISAP 2010), ASCE Geotechnical Special Publication GSP 203, Nagoya, Japan.

[11] Molenaar, A., Characterization of some tropical soils for road pavements. Journal of the Transportation Research Board, Transportation Research Record, 1989(1), pp. 186-193, 2007. doi: http://dx.doi.org/10.3141/1989-63

[12] CEN, Unbound and Hydraulically Bound Mixtures - Part 47: Test Method for the Determination of California Bearing Ratio, Immediate Bearing Index and Linear Swelling, EN 13286-47. European Committee for Standardization (CEN): Brussels, 2004. 